most difficult to organise such a unit could be grafted on to existing day hospitals to avoid capital expenditure and large running costs. Certainly a day unit or domiciliary service represents a relatively easy way of starting to meet the needs of dying patients and their families; but a back-up of beds and hospital facilities is also needed $-83 \%$ of our patients died as inpatients. Moreover, patients seem to find it convenient and reassuring to have the day hospital integrated with the inpatient unit. We believe that this should be the arrangement of choice and the pattern of the future.

Mrs Linda Liddamant collected and analysed the data under the supervision of Mrs Maureen Naylor. Secretarial assistance was provided by Mrs Sheila Harris. Valuable advice was received from Professor J Knowelden. Grateful thanks are due to the nurses, rehabilitation professionals, and all other colleagues who have sustained this enterprise.

\section{References}

1 Wilkes, E, Proceedings of the Royal Society of Medicine, 1974, 67, 1001

2 Wilkes, E, Nursing Times, 1977, 73, 1506.

3 Ward, A M W, Social Science and Medicine, 1974, 8, 413.

(Accepted 17 fuly 1978)

\title{
Detection of a new antibody system reacting with Dane particles in hepatitis $B$ virus infection
}

\author{
A ALBERTI， S DIANA， G H SCULARD, A L W F EDDLESTON, ROGER WILLIAMS
}

British Medical fournal, 1978, 2, 1056-1058

\section{Summary and conclusions}

Antibodies in the serum reacting with antigens on the surface of radiolabelled Dane particles distinct from hepatitis $B$ surface and core antigens (HBsAg and HBcAg) were detected, using a double antibody precipitation assay, in 12 out of 15 patients early in the course of acute type $B$ hepatitis and at the time of disappearance of circulating Dane particles. No such antibody activity was found in 15 of the 16 patients with HBsAg-positive chronic active hepatitis, 13 of whom had complete Dane particles in the serum. In a group of 16 asymptomatic HBsAg carriers (without Dane particles in serum) antibody activity was shown in nine.

This demonstration of antibodies precipitating Dane particles may be relevant to the clearance of circulating hepatitis $B$ virions and the termination of infection in acute type $B$ hepatitis. Their absence in all but one of the cases of chronic active hepatitis might explain why the virus infection persists in this group of patients.

\section{Introduction}

Recovery from acute hepatitis type $\mathrm{B}$, as with many other virus infections, is probably a complex process in which lymphocytes, macrophages, neutralising antibody, and interferon all play a part. Cytotoxic, virus-specific $\mathrm{T}$ lymphocytes ${ }^{12}$ are likely to be important in removing infected hepatocytes, but the mechanisms that prevent reinfection of liver cells and clear the virus from the

Liver Unit, King's College Hospital and Medical School, London SE5 A ALBERTI, MD, research fellow (present address: Instituto di Medicina Clinica, Patologia Medica, Policlinico dell Universita, 35100 Padova, Italy)

$S$ DIANA, MD, research fellow

G H SCULLARD, MB, MRCP, research fellow

A L W F EDDLESTON, DM, MRCP, senior lecturer and consultant physician

ROGER WILLIAMS, MD, FRCP, director and consultant physician circulation are poorly understood. Dane particles, which represent the complete hepatitis $B$ virion, ${ }^{3} \cdot$ disappear from the blood early in the course of acute hepatitis B, while the small round particles consisting solely of surface coat antigen ( $\mathrm{HBsAg}$ ) usually persist for much longer. ${ }^{4}$ Detection of anti-HBs is a late and inconstant finding, ${ }^{3}$ and although antibody reacting with the core of the Dane particle (anti-HBc) is present earlier in the illness, this does not react with the intact virion and cannot, therefore, be implicated in clearance of the virus. In healthy HBsAg carriers large amounts of $\mathrm{HBsAg}$ but not of Dane particles are usually detected in serum. ${ }^{7}$ Thus the immune mechanisms responsible for removing Dane particles may be different from those involved in $\mathrm{HBsAg}$ clearance. Indeed, aggregation of Dane particles by sera free of anti-HBs has been shown by electron microscopy. ${ }^{8}$

We report here the detection in acute type $B$ hepatitis of antibodies reacting with new specificities on Dane particles. The absence of such anti-Dane activity in most cases of chronic active hepatitis may explain the persistence of hepatitis $B$ virus infection in these patients.

\section{Patients and methods}

We investigated three groups of patients. Fifteen patients had acute hepatitis type B; within three months of the onset of hepatitis they recovered completely and $\mathrm{HBsAg}$ was cleared from their sera. Sixteen patients had HBsAg-positive chronic active hepatitis proved on biopsy; at the time of presentation eight were untreated while eight had been on immunosuppressive drugs (prednisolone and azathioprine) for four to 24 months. The third group comprised 16 asymptomatic $\mathrm{HBsAg}$ carriers whose liver biopsies showed either normal histology (seven cases); minor abnormalities including hydropic changes (one case) or fatty changes (one case); or focal parenchymal necrosis (seven cases). All the carriers with focal parenchymal necrosis and the carrier with hydropic changes had only scattered liver cells positive for HBsAg in the cytoplasm of the hepatocytes as shown by the orcein method or by immunofluorescence, while in the other eight patients there were many sheets of $\mathrm{HBsAg}$-positive cells. ${ }^{9}$

RADIOIMMUNOASSAY FOR ANTIBODIES TO DANE PARTICLES

The principle of the assay is to label complete Dane particles with ${ }^{3} \mathrm{H}$-thymidine using their own endogenous DNA polymerase and then to incubate them with the serum under test. Antibody-coated virions 
are precipitated by adding anti-immunoglobulin serum, and the loss of radioactivity from the supernatant is then a measure of the antiDane antibody activity.

A preparation enriched in Dane particles was obtained by density gradient ultracentrifugation ${ }^{10}$ from sera of $\mathrm{HBs} A g$ carriers with high levels of DNA polymerase activity associated with Dane particles. Dane particles in this preparation were labelled by the DNA polymerase reaction with ${ }^{3} \mathrm{H}$-thymidine triphosphate $\left({ }^{3} \mathrm{H}-\mathrm{TPP}\right.$, Radiochemical Centre, Amersham, England) and then dialysed extensively against TRIS buffer ( $\mathrm{pH} 7 \cdot 4)$. That the labelled Dane particles were still intact after this procedure was shown by the finding that $97 \%$ were precipitated by rabbit anti-HBs sera (Behringwerke, West Germany) but only $4 \%$ by human high-titre anti-HBc sera. In the assay system $50 \mu \mathrm{l}$ of labelled Dane particles (about 300 ${ }^{3} \mathrm{H} \mathrm{cpm}$ ) was mixed with $50 \mu \mathrm{l}$ of sera (diluted $1 / 10$ ), and after 72 hours at $4^{\circ} \mathrm{C}$ immune complexes were precipitated with $200 \mu l$ of anti-immunoglobulin sera (Miles Laboratories). After a further 18 hours' incubation the tubes were centrifuged at $3000 \mathrm{rpm}$ for 30 minutes and the ${ }^{3} \mathrm{H} \mathrm{cpm}$ in $200 \mu \mathrm{l}$ supernatant was measured.

Percentage precipitation $=100-\frac{{ }^{3} \mathrm{H} \mathrm{cpm} \mathrm{serum}-{ }^{3} \mathrm{H} \mathrm{cpm} \mathrm{TCA}}{{ }^{3} \mathrm{H} \mathrm{cpm} \mathrm{buffer}-{ }^{3} \mathrm{H} \mathrm{cpm} \mathrm{TCA}} \times 100 \%$ where ${ }^{3} \mathrm{H} \mathrm{cpm}$ TCA represented cpm detected in $200 \mu \mathrm{l}$ of supernatant with $200 \mu \mathrm{l}$ of $25 \%$ trichloroacetic acid added instead of the anti-immunoglobulin serum and ${ }^{3} \mathrm{H} \mathrm{cpm}$ buffer those detected when $50 \mu \mathrm{l}$ of buffer was substituted for $50 \mu \mathrm{l}$ of serum.

Sera from 16 normal subjects, all negative for $\mathrm{HBsAg}$ and anti$\mathrm{HBs}$ by radioimmunoassay, gave a mean percentage precipitation of $1.88 \pm 11.56$. In one of these subjects the value was significantly higher than in the others at $39^{\circ}$, , which was 3.3 standard deviations higher than the mean for the whole group $(\mathrm{P}<0.0005)$. This patient was therefore excluded, giving a mean normal value of $-0.8 \pm 6.5 \%$ and an upper limit of $12 \cdot 2 \%$ (mean $+2 \mathrm{SD})$.

\section{SEROLOGICAL TESTS}

HBsAg and anti-HBs were tested by solid phase radioimmunoassay (Abbott). HBsAg was titred by passive haemagglutination (Hepatest, Wellcome). Anti e antigen (anti-HBe) was investigated by immunodiffusion. Hepatitis B virus-specific DNA polymerase was measured in sera using twentyfold concentrated pellets, ${ }^{11}$ the upper limit of the normal range being $250{ }^{3} \mathrm{H} \mathrm{cpm}$.

\section{Results}

In 12 of the 15 patients with acute hepatitis the serum samples obtained within six days of presentation were found to contain antibodies reacting with Dane particles (fig 1). Specificity testing carried out with sera from two of these patients showed that precipitation of Dane particles in the assay was reduced by $57.1 \%$ and by $69.9 \%$ when $50 \mu \mathrm{l}$ of unlabelled Dane particles was added. In contrast, the addition of $50 \mu \mathrm{l}$ of purified HBsAg prepared by density gradient ultracentrifugation ${ }^{12}$ and containing only small round forms on electron microscopy had no effect, although this preparation had the same HBsAg titre as that containing the unlabelled Dane particles. Sera from all 15 patients were negative for anti-HBs by radioimmunoassay and contained no detectable anti-HBe, confirming the suggestion that the anti-Dane antibodies were reacting with different specificities.

In 10 patients, all positive for Dane-particle antibodies, further samples were tested 15 and 30 days after presentation. Four had become negative, while precipitating antibodies could still be detected in the other six (fig 2). Three patients in whom no significant precipitation was observed in the first serum sample were also negative in two further follow-up samples. Complete Dane particles had already disappeared from the circulation in the first serum sample in eight cases, as shown by the absence of DNA polymerase activity, and all these eight patients were positive for antibodies to Dane particles. The remaining four patients who had antibodies to Dane particles in their first serum samples had raised DNA polymerase levels $\left(516-1036{ }^{3} \mathrm{H} \mathrm{cpm}\right)$, indicating that complete virions were still present in the circulation. These had, however, disappeared by the time the next serum sample was taken (fig 2). Clearance of virions was slower in two of the three patients with no detectable antibodies to Dane particles, both still being positive for DNA polymerase 15 days after presentation (fig 2).

In contrast to the findings in acute hepatitis, only one of the 16 patients with $\mathrm{HBsAg}$-positive chronic active hepatitis had serum

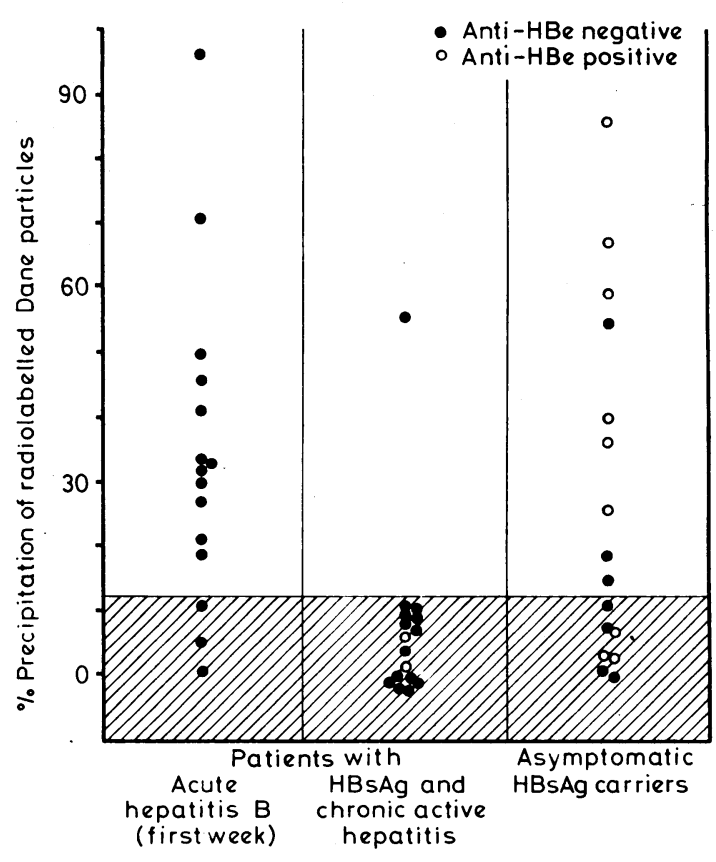

FIG 1-Percentage of radiolabelled Dane-particles precipitated when sera from various patient groups were used in the radioimmunoassay. Shaded area shows normal range.

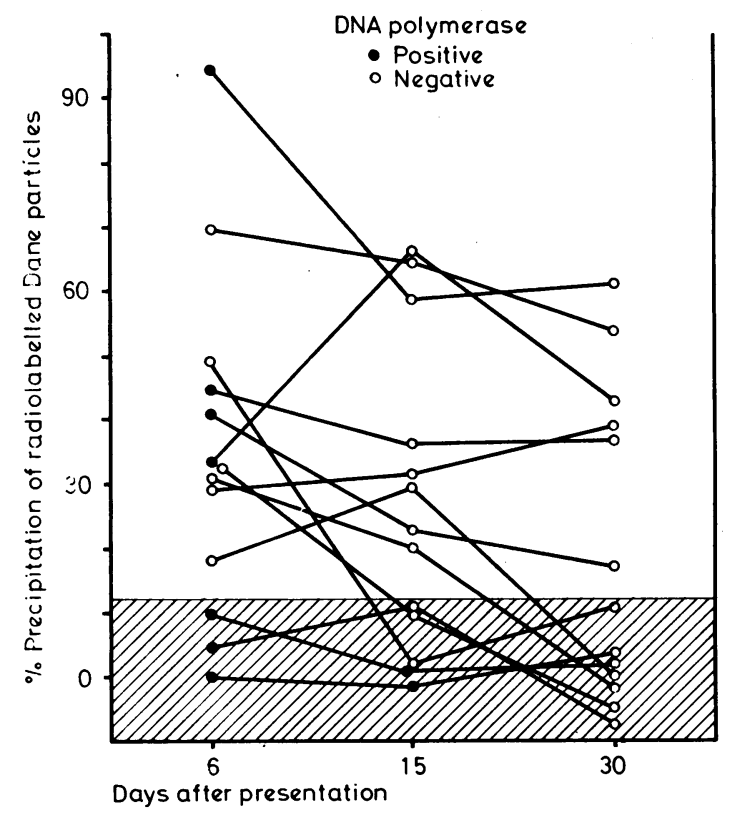

FIG 2-Values of Dane-particle precipitation obtained with serial serum samples from patients with acute hepatitis $B$. Broken line shows upper limit of normal range.

antibodies reacting with Dane particles. Thirteen of these 16 patients had complete Dane particles in serum with levels of DNA polymerase activity ranging from 261 to $837{ }^{3} \mathrm{H} \mathrm{cpm}$. Anti-HBe was found in two cases, but neither had antibodies reacting with Dane particles.

Asymptomatic HBsAg carriers-Only two of the eight carriers with extensive sheet distribution of $\mathrm{HBsAg}$-positive liver cells had circulating antibodies to Dane particles compared with seven out of the eight cases, including six of the seven with focal parenchymal necrosis, who had scattered HBsAg-positive hepatocytes $(P<0.02)$. DNA polymerase was not detected in any case, suggesting the absence of complete Dane particles in serum. None of the 16 carriers had anti-HBs by radioimmunoassay, and of the nine patients with anti$\mathrm{HBe}$ six were positive and three were negative for Dane-particle antibodies (fig 1). In two of the positive cases the addition of unlabelled 
Dane particles to the assay system significantly reduced the precipitation of labelled particles $(-55.3 \%$ and $-61.5 \%$ respectively), while the addition of small round particles (with the same HBsAg titre) had little effect $(+3.3 \%$ and $-1.2 \%$ respectively).

\section{Discussion}

Our finding of antibodies reacting with antigenic determinants at the surface of the Dane particle in sera free of anti-HBs implies that the antigens taking part in this reaction are distinct from the HBsAg. The failure of a preparation containing small round forms of $\mathrm{HBsAg}$ but free of Dane particles to block the reaction together with the clear reduction in binding after the addition of a preparation enriched in Dane particles are further evidence in support of this view. Similarly, although antibodies to the $\mathrm{HBcAg}$ were likely to have been present in the sera of most of these patients, ${ }^{13}$ the absence of Dane-particle precipitation using high-titre anti-HBc serum excluded any involvement of this antibody in the test system. Moreover, negative results were obtained in most of the patients with $\mathrm{HBsAg}$-positive chronic active hepatitis, in whom the highest titres of anti-HBc are detected. ${ }^{14}$

The finding by Neurath $e \mathrm{al}^{8}$ that sera from one asymptomatic $\mathrm{HBsAg}$ carrier, free of anti-HBs but positive for anti-HBe, could aggregate Dane particles but not small round forms of HBsAg led them to suggest that this was due to the presence of $\mathrm{HBeAg}$ on the surface of Dane particles. In our series there was no correlation between anti-HBe and anti-Dane antibodies. The e antigen system has, however, been shown to be heterogeneous, ${ }^{15}$ and it is possible that only one of the various $\mathrm{HBeAg}$ determinants is implicated.

These antibodies to Dane particles appearing early during acute infection might help to eliminate the complete hepatitis $B$ virus, and their absence in patients with chronic active hepatitis may explain why the infection persists with continuation of active virus replication. Indeed, in most of the patients with chronic active hepatitis, DNA polymerase activity was detected in serum, indicating the presence of complete Dane particles. These circulating virions are unlikely to have interfered with the detection of anti-Dane antibodies since negative results were also obtained in the three cases without DNA polymerase activity. Furthermore, levels of enzyme activity, when present, were lower in chronic active hepatitis than in acute hepatitis.

The striking difference in the frequency of antibodies to Dane particles between asymptomatic HBsAg carriers with normal liver histology and those showing focal parenchymal necrosis suggests that these two groups differ in their immune response to the infection. This agrees with the findings of El Sheikh et al, ${ }^{2}$ who showed that $\mathrm{T}$-lymphocyte sensitisation to $\mathrm{HBsAg}$ is present only in the cases of focal parenchymal necrosis. In recent studies we have also been able to show that only in these cases can $\mathrm{HBcAg}$ be detected in a few liver cells (unpublished). In the patients with focal parenchymal necrosis active replication of the virus may continue in a few liver cells, although Dane particles are not detected in serum as they are rapidly removed by the circulating antibodies we have shown. These might also limit the spread of the virus to uninfected cells, thus explaining the finding of only a few hepatocytes containing viral antigens and the absence of more severe liver damage. These cases could represent a slow resolving hepatitis following a subclinical course from the onset, and, indeed, about a quarter of a similar group of patients have been shown to eventually clear $\mathrm{HBsAg}$ 12 to 24 months after its first detection (Realdi, personal communication). In those carriers with normal liver histology there is usually no evidence of replication of the complete virion, and the absence of anti-Dane antibodies in these cases may simply reflect the absence of antigenic stimulus.

We thank Professor A J Zuckerman and Mrs Y White for HBsAg and anti-HBs testing and Linda Rimmer for editorial help. AA was in receipt of an Anna Villa Rusconi Foundation Fellowship, and the work was also supported by the Wellcome Trust.

\section{References}

1 Alberti, A, et al, Gut, 1977, 18, 1004.

${ }^{2}$ El Sheikh, N, et al, Clinical and Experimental Immunology, 1978, 31, 158. ${ }^{3}$ Robinson, W S, and Lutwich, L I, New England fournal of Medicine, 1976, 295, 1168.

4 Alberti, A, et al. Submitted for publication.

${ }^{5}$ Krugman, S, and Giles, J P, New England fournal of Medicine, 1973, 288, 755

${ }^{6}$ Ibrahim, A B, Vyas, G N, and Perkins, H A, Infection and Immunity, $1975,11,137$.

${ }^{7}$ Nielsen, J O, Nielsen, M H, and Elling, P, New England fournal of Medicine, 1973, 288, 484.

${ }^{8}$ Neurath, A R, et al, fournal of General Virology, 1976, 30, 277.

${ }^{9}$ Portman, B, et al, Gut, 1976, 17, 19.

10 Robinson, W S, and Greenman, R L, fournal of Virology, 1974, 13, 1231.

11 Kaplan, P M, et al, fournal of Virology, 1973, 12, 995.

12 Gerin, J L, Holland, P V, and Purcell, R H, fournal of Virology, 1971, 7, 569.

${ }^{13}$ Hoofnagle, J H, Gerety, R J, and Barker, L F, Lancet, 1973, 2, 869.

14 Hadzyannis, S J, and Karvountzis, G G, Digestion, 1976, 14, 460.

15 Williams, A, and Le Bouvier, G L, Bibliotheca Haematologica, 1976, 42, 71.

(Accepted 13 September 1978)
ONE HUNDRED YEARS AGO The returns asked for by the Society of Arts from the medical officers of health throughout the country as to their water-supply are now, it is reported, as complete as it is likely they will be. It was intended that they should all have been sent in and printed for the use of the Conference on Water-Supply, held at the request of the Prince of Wales. Such as were ready were then printed and circulated; but many returns have arrived since, and these have been, with the others, issued in the society's journal, accompanied by a request that any further available information should be communicated. There are now altogether some one hundred and six replies received; and, coming as they do from all parts of the country, from towns and rural districts, from manufacturing, agricultural, and mining communities, they give a fair idea of the existing state of water supply. The first question inquired what was the source of supply, and the replies to this are of course various; but the great difference in answers to the second question, as to what is the daily amount of supply per head, is astonishing. It ranges from $4 \frac{1}{2}$ gallons per head per day up to 40 , and in a large number of cases the supply is reported as constant. The lowest supplies mentioned in the returns

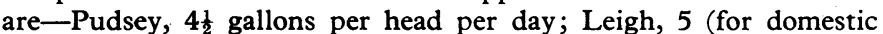
purposes); Morley, 6; Colne and Marsden, 5 in summer, "very uncertain", and here "notices are up to forbid swilling steps, cleaning windows, etc." Ossett has 10 , St. Helen's $12 \frac{1}{2}$, Whitby 15; but the majority of returns are from 20 to 30 . The replies to the question, "Can you give any information from your own observation of sewagepolluted water spreading epidemic diseases ?" give useful additional information to the official reports of the Local Government Board. In some cases, the spread of typhoid fever is merely referred to as "probably due" to sewage-contamination; but there are several in which not only are the cases directly traced to sewage-polluted water, but with a change of water the epidemic has ceased. The returns should be seen by those who have the charge of local sanitary arrangements. Two cases are mentioned of the spread of fever by milk mixed with sewage-polluted water. The attempt to elicit information about the effect of water on health and the production of diseases not epidemic has not been so successful; but diarrhoea, dyspepsia, and malaise are in many cases referred to. Diphtheria, too, is several times mentioned. The return from Chadderton (near Oldham) gives a good typical instance of the ignorance throughout the country generally on water-supply. The medical officer found a cesspool near a pump, and asked the farmer what he did with the contents. "Strange to say," he replied, "the cesspool never needs to be cleaned out." The reason is obvious: the excrement in a liquid state filtered into the well, and no one suffered till the outbreak of typhoid epidemic. (British Medical fournal, 1878.) 